\title{
MARIA SACHIKO CECIRE, HANNAH FIELD, KAVITA MUDAN FINN OCH MALINI ROY (RED.) SPACE AND PLACE IN CHILDREN'S LITERATURE, I 789 TO THE PRESENT
}

Farnham: Ashgate Publishing Ltd, 2015 (250 s.)

Lennart Helsing ser i Tankar om barnlitteraturen (1963) fyra uppgifter för barnboken: att lära barnet behärska språket, att orientera barnet i tiden och rummet, att orientera barnet socialt samt att "påverka barnet mer direkt, att suggerera fram - eller kanske snarare aktivera - själva livskänslan". Annorlunda uttryckt kan man säga att barnlitteratur handlar dels om att lära sig att orientera sig i tillvaron, dels om att väcka förmågan att skapa andra världar, bortom vardagens, till liv. Sett ur det perspektivet är kanske rummet en aspekt som är mer angelägen när det gäller barnlitteratur än andra litteraturtyper.

I antologin Space and Place in Children's Literature, 1789 to the Present (2015) argumenterar redaktörerna Maria Sachiko Cecire, Hannah Field, Kavita Mudan Finn och Malini Roy för att så kan vara fallet. Antologin innehåller tio bidrag, vilka utforskar såväl metaforiska som fysiska rums och platsers betydelser i barnlitteraturen. Utöver redaktörerna finns texter av Peter Hunt, Aneesh Barai, Francesca Orestano, Renata Morresi, ElzetteSteenkamp, Ruth Feingold, Margot Stafford och Catherine Renaud. Ett genomgående tema är hur makt, kunskap och identitet skapas och/eller åskådliggörs i och runt om litteraturen. Primärmaterialet består av barn- och ungdomslitteratur från sent 1700-tal till idag, från i första hand engelskspråkiga länder. Där finns allt från en artikel om Sylvia Plaths relativt okända barnböcker till en om Jenny Robsons futuristiska ungdomsbok $\mathrm{Sa}$ vannah 2116 AD (2005). Bidrag om den franske bilderboksförfattaren Claude Ponti och om latinamerikanska bilderböcker utgör två språkliga undantag.

Samlingen är sprungen ur en konferens på samma tema, vilken hölls vid Oxfords universitet 2009. Det har alltså tagit redaktörerna sex år att färdigställa antologin, vilket också märks. Det är en ovan-

(C2016 Lydia Wistisen. This is an Open Access article distributed under the terms of the Creative Commons Attribution-Noncommercial 3.0 Unported License (http://creativecommons.org/ licenses/by-nc/3.0/), permitting all non-commercial use, distribution, and reproduction in any medium, provided the original work is properly cited.

Citation: Barnboken - tidskrift för barnlitteraturforskning/Barnboken - Journal of Children's Literature Research, Vol. 39, 2016 http://dx.doi org/10.14811/clr.v39i0.248 
ligt välkomponerad konferensantologi. För det är svårt att omvandla en konferens till en bok, ofta framstår resultatet som spretigt och svårtillgängligt. I Space and Place in Children's Literature har redaktörerna löst detta genom att dela in arbetet i fyra delar, vilka alla inleds av ett kort introducerande stycke följt av en serie tips för vidare läsning. Mycket tack vare dessa introduktioner känns verket till sin helhet genomtänkt och lättåtkomligt. Det är även läsar- och kanske framför allt studentvänligt. För den som vill vidareutveckla någon av alla de idéer som presenteras i antologin finns mycket att hämta.

I inledningen framhäver Sachiko Cecire, Field, Mudan Finn och Roy hur vanligt det är inom en barnlitterär kanon med gestaltningar av fantastiska landskap som enbart barn kan nå. Platser som Underlandet, Landet ingenstans och Narnia korresponderar med en syn på barndomen som en annan värld, åtskild från vuxenvärldens verklighet. Eftersom de imaginära världarna är skilda från vardagen är de också utmärkta platser för experiment och lek med makt och identitetskonstruktion. Detta förhållande utpekas som tanken bakom antologins maktperspektiv.

Maktperspektivet har stått i centrum också inom de senaste decenniernas utveckling av en rumsteoretisk metodologi inom litteraturforskningen i stort. Sedan slutet av 1900-talet har identitetsfrågor upptagit en allt större plats i rumsteoretiska diskussioner, framför allt $i$ anknytning till identiteter som på olika sätt marginaliserats. Redan Franco Moretti, vars studie Atlas of the European Novel 1800-1900 (1998) utgör ett pionjärarbete inom fältet, argumenterade för att social ställning inverkar på framställningen av rummet $i$ litteraturen. Till exempel visar hans analyser av 1800-talets skönlitterära London och Parisskildringar att borgerliga kvarter ger upphov till en helt annan typ av berättelse än kvarter befolkade av arbetarklass.

Trots att rumsteorin är en väletablerad tradition inom litteraturvetenskapen finns $i$ antologin en tendens till att negligera tidigare insatser inom fältet. I några av de enskilda bidragen placeras den egna textens teoretiska ramverk i en större kontext av tankar från såväl litteraturforskning som sociologi, filosofi och kulturgeografi, men i inledningen verkar författarna snarare vilja etablera en egen forskningslinje. De redogör för geografen Yi-Fu Tuans och sociologen Michel de Certeaus tankar om rum, plats och makt men drar sedan en direkt linje mellan dem och undersökningar av rummet i barnlitteraturen, som Pauline Dewans The House as Setting, Symbol, and Structural Motif in Children's Literature (2004) och Jane Carrolls Landscape in Children's Literature (2012). Detta gör att många av de idéer som presenteras går miste om halva sitt sammanhang. Jag saknar till 
exempel en diskussion av den inom samtida barn- och ungdomslitteraturforskning så populära ekokritiken. Då Dewans och Carrolls studier brottas med samma problem är det lätt att tolka det som en genomgående tendens att friställa sig från övrig litteraturforskning.

I Space and Place in Children's Literature rör detta problem emellertid enbart inledningen. Resten av antologin är indelad i fyra tematiska avsnitt. Det första, "The Spaces between Children and Adults", diskuterar det implicita rummet mellan barn och vuxna utifrån bland annat Jacqueline Roses The Case of Peter Pan (1984). Avsnittets två bidrag bygger vidare på den kritik av Roses arbete, som nyligen framfördes av David Rudd i artikeln "Children's Literature and the Return to Rose" (2010). Hunt och Aneesh Barai visar hur avståndet mellan barn och vuxen inte behöver vara något negativt. Det kan istället fyllas med mening och fungera som ett rum för samtal mellan barn och vuxen.

Det andra avsnittet, "Real-World Places", behandlar verkliga platsers funktion i litteraturen, med särskilt fokus på känslan av att "höra hemma" eller ha sina "rötter" på en särskild plats. Här aktiveras makt- och identitetsfrågor utifrån andra premisser än i den föregående delen. Bland annat driver Orestano tesen att reseskildringen i barnlitteratur ofta används för att etablera en nationell identitet. Mötet med den främmande platsen blir för den unga läsaren ett sätt att få syn på sig själv. Här finns också en diskussion om vem barnet är, vilken jag saknade dels i inledningen, dels i några av de andra avsnittens introduktioner. Eftersom antologin framför allt vill säga något om rum och identitet hade en inledande diskussion om den tänkta läsarens subjektpositionering varit bra. Det finns ibland en tendens till att tala om barn och vuxna som fasta kategorier och glömma att också kön, klass och etnicitet inverkar på framställningen.

I den tredje delen, "Traversing the Imaginary", står barnlitteraturens många fantastiska miljöer i fokus. Sachiko Cecire, Feingold och Stafford visar hur barnfantastiken uppfinner nya världar i syfte att skapa alternativ till det reella samhällets nationella och kulturella maktordning. Också här är det tydligt att det främmande många gånger används i syfte att stärka bilden av det egna.

Slutligen behandlas barnbokens egen geografi. I "Book Space" undersöks barnbokens materiella premisser av Field och Renaud. De skriver båda om bilderböcker, dels om viktorianska panoraman för barn, dels om Pontis avantgardistiska verk. Eftersom författarna utgår från boken som objekt bjuder detta avsnitt på perspektiv som i grunden skiljer sig från de tidigare. Särskilt intressant blir det i relation till antologins övergripande makt-, kunskap- och identitetste- 
ma. Inbjuder exempelvis en bilderbok mer än annan litteratur till en läsning mot den vuxne författarens intentioner?

Ett trevligt inslag i Space and Place in Children's Literature är den epilog som Philip Pullman har skrivit. Pullman är författare till bland annat fantasytrilogin His Dark Materials (1995-2000) och mottagare av flera prestigefyllda barn- och ungdomslitteraturpriser. Hans text drivs av en entusiastisk läsares begär efter bilder och berättelser och utgör ett välkommet avslut på antologins många diskussioner. Den innehåller flera illustrationer samt en diskussion av det gränsland som öppnas mellan den som läser och texten. Eftersom vissa delar av landskapet tillhör verket och andra läsaren är det sig aldrig likt utan transformeras ständigt av minnen, erfarenheter och associationsmönster, menar Pullman. Läsning är och förblir en privat angelägenhet, en monogam relation.

Pullman diskuterar ett antal gränsland, till vilka han själv ständigt återvänder. För att återgå till Hellsing är det tydligt att man genom att fokusera på rummets betydelse i barnlitteraturen kan undersöka just hur barnet kommer i kontakt med språket och omvärlden, lär sig orientera sig i tiden, rummet och fantasins värld. Pullmans epilog visar att denna process fortgår hela livet. Livskänslan upphör aldrig att aktiveras av litteraturen. Språket och förhållandet till omvärlden kan alltid utvecklas och fördjupas.

Lydia Wistisen

Doktorand i litteraturvetenskap

Stockholms universitet 